This document is confidential and is proprietary to the American Chemical Society and its authors. Do not copy or disclose without written permission. If you have received this item in error, notify the sender and delete all copies.

\title{
Development of a Passive Sampling Technique for Measuring Pesticides in Waters and Soils
}

\begin{tabular}{|r|l|}
\hline Journal: & Journal of Agricultural and Food Chemistry \\
\hline Manuscript ID & Draft \\
\hline Manuscript Type: & Article \\
\hline Complete List of Authors: & $\begin{array}{l}\text { Li, Yanying; Lancaster Environment Centre } \\
\text { Chen, Chang-Er; Stockholms Universitet, Environmental Research } \\
\text { Institute } \\
\text { Chen, Wei; Lancaster Environment Centre } \\
\text { Chen, Jingwen; Dalian University of Technology, School of Environmental } \\
\text { Science and Technology } \\
\text { Cai, Xiyun; Dalian University of Technology, } \\
\text { Jones, Kevin; Lancaster University, Lancaster Environment Centre } \\
\text { Zhang, Hao; Lancaster University, Lancaster Environment Centre }\end{array}$ \\
\hline
\end{tabular}

\section{SCHOLARONE \\ Manuscripts}




\section{Development of a Passive Sampling Technique for}

\section{Measuring Pesticides in Waters and Soils}

4 Yanying $\mathrm{Li}^{1}$, Chang-Er L. Chen ${ }^{1 \wedge}$, Wei Chen ${ }^{1 \#}$, Jingwen $\mathrm{Chen}^{2}$, Xiyun $\mathrm{Cai}^{2}$, Kevin C. Jones ${ }^{1 *}$, 5 Hao Zhang ${ }^{1 *}$

7 1. Lancaster Environment Centre, Lancaster University, Lancaster, LA1 4YQ, UK

8 2. Key Laboratory of Industrial Ecology and Environmental Engineering (MOE), School of

9 Environmental Science and Technology, Dalian University of Technology, Linggong Road 2,

10 Dalian 116024, China

$11 \wedge$ Current address: Environmental Research Institute, MOE Key Laboratory of Environmental

12 Theoretical Chemistry, South China Normal University, Guangzhou, 510006, China

13 \# Current address: State Key Laboratory of Environmental and Biological Analysis, Department

14 of Chemistry, Hong Kong Baptist University, Kowloon Tong, Hong Kong SAR, China.

$15 *$ corresponding authors

16 E-mail: k.c.jones@lancaster.ac.uk; Tel: 44-1524 510230; h.zhang@lancaster.ac.uk; Tel: +44 1524

$17 \quad 593899$.

18 


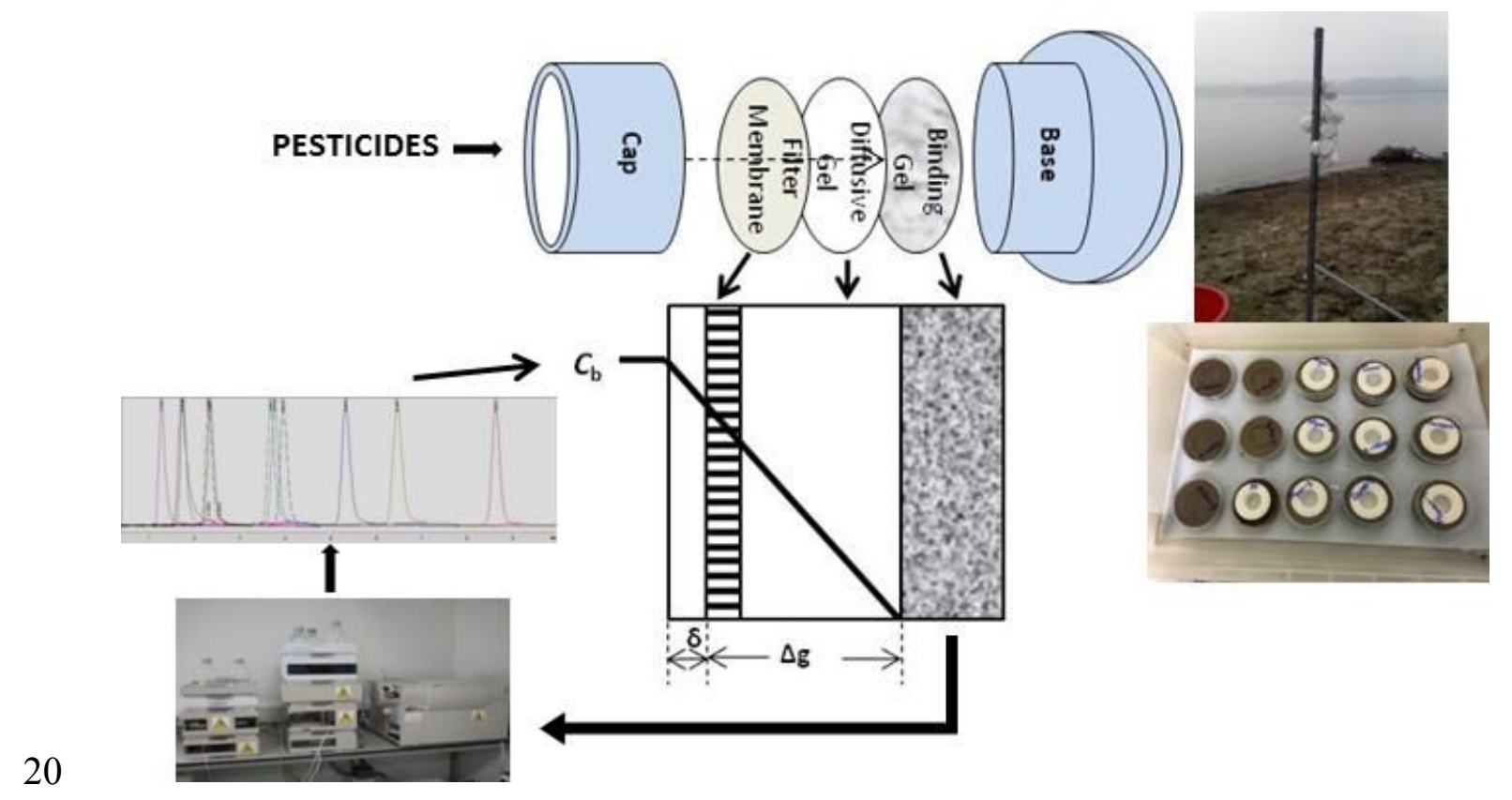




\section{ABSTRACT}

23 It is essential to monitor pesticides in the environment to help ensure water and soil quality. The

24 diffusive gradients in thin-films (DGT) technique can measure quantitative in-situ labile (available)

25 concentrations of chemicals in water, soil and sediments. This study describes the systematic

26 development of the DGT technique for 9 current pesticides, selected to be representative of

27 different classes with a wide range of properties, with two types of resins (HLB (hydrophilic-

28 lipophilic-balanced) and XAD 18) as binding layer materials. The masses of pesticides

29 accumulated by DGT devices were proportional to the deployment time and in inverse proportion

30 to the thickness of the diffusive layer, in line with DGT theoretical predictions. DGT with both

31 resin gels were tested in the laboratory for the effects of typical environmental factors on the DGT

32 measurements. DGT performance was independent of: $\mathrm{pH}$ in the range of 4.7 - 8.2; dissolved

33 organic matter concentrations $<20 \mathrm{mg} \mathrm{L}^{-1}$; and ionic strength from 0.01 to $0.25 \mathrm{M}$, although it was

34 slightly affected at $0.5 \mathrm{M}$ in some cases. This confirms DGT as a sampler suitable for controlled

35 studies of environmental processes affecting pesticides. Field applications of DGT to measure

36 pesticides in situ in waters and controlled laboratory measurements on five different soils (prepared

37 at fixed soil:water ratios) demonstrated DGT is a suitable tool for environmental monitoring in

38 waters and for investigating chemical processes in soils. 


\section{INTRODUCTION}

41 Pesticides contribute significantly to food production. However, their potential adverse effects on

42 the environment, biodiversity, food quality and human health have raised concerns. Pesticides

43 enter soil systems through direct application, ${ }^{1}$ or indirect pathways such as wash-off from treated

44 foliage, ${ }^{2}$ crop residues, leaf fall and root exudates. ${ }^{3}$ Only a small proportion of applied pesticides

45 reach the target pests, ${ }^{4}$ with typically $>99 \%$ remaining in soils. This may cause unintended

46 environmental effects as pesticides can be hazardous to the indigenous microorganisms, including

47 beneficial competitors, predators and parasites of target pest insects. ${ }^{5}$ Studies have shown that

48 pesticides inhibit soil microbial diversity and activities, ${ }^{6,7}$ adversely influence soil biochemical

49 processes and disturb soil ecosystems. ${ }^{8}$ In recent decades there has been increasing concern that

50 pesticides constitute a risk to humans by entering the food chain, ${ }^{9}$ through direct contact with soil,

51 inhalation of volatile pesticides, ${ }^{10}$ and through groundwater contamination by pesticides leaching

52 from soils.

53 It is clear that measurements of pesticides in soils are needed to understand their fate and

54 dissipation. These are usually performed using various extraction methods, ${ }^{11}$ which can be

55 complicated, expensive, laborious and time-consuming. ${ }^{12}$ These extraction methods usually focus

56 on the 'total concentration', although some of them could be related to the bioavailable fraction,

57 which is more relevant in risk assessment. However, they cannot provide any kinetic parameters

58 of in situ soil processes of pesticides, such as i) exchange between soil solution and solid phase

59 and ii) resupply kinetics in response to biological uptake. Therefore, a technique which considers

60 kinetic aspects and bioavailability would be of great benefit.

61 Pesticides can enter surface waters through diffuse pollution and leaching. ${ }^{13}$ There are

62 requirements to monitor pesticides to assess water quality. Grab sampling, which is widely used 
63 in water monitoring, is an effective way to measure the occurrence of organic contaminants in

64 aquatic systems, but it only provides snapshot information at the time of sample collection;

65 episodic contaminant events may be missed. ${ }^{14,15}$ The development of passive sampling approaches,

66 which can give time-weighted average (TWA) concentrations, has therefore increased in recent

67 years.

68 Passive samplers are able to retain trace analytes by pre-concentration; the in situ sampling does

69 not affect the environment. ${ }^{16}$ Passive samplers also limit the degradation of trapped chemicals

70 during transport and storage. ${ }^{17}$ Techniques such as POCIS (polar organic chemical integrative

71 sampler), Chemcatcher ${ }^{18,19}$, ceramic dosimeters ${ }^{20}$ and microporous samplers ${ }^{21}$ are currently used

72 for the measurement of pesticides in waters. However, they are dependent on hydrodynamic

73 conditions during field deployment and/or rely on a laboratory calibration and losses of

74 performance reference compounds to estimate sampling rates..$^{22}$ DGT (diffusive gradients in thin-

75 films) is a passive sampling technique which can be used for field deployment without

76 calibration. ${ }^{23}$ It is also a 'dynamic' technique that can be used in soils for measuring bioavailable

77 species. $^{24}$

78 The development and use of DGT for inorganics has a long and well-published pedigree. The

79 principles were first published in 1994 in Nature $^{25}$ and now over 800 peer-reviewed papers have

80 been published on testing and applying the technique in different environmental media, such as

81 waters, ${ }^{26,}{ }^{27}$ soils ${ }^{28}$ and sediments. ${ }^{29}$ Until recently, the focus has been on metals, nutrients and

82 radionuclides. DGT typically utilizes a three-layer system: a resin-impregnated hydrogel layer, a

83 hydrogel diffusion-layer and a filter membrane. The thick diffusion gel layer which controls the

84 uptake of analytes into the receiving phase limits the influence of hydrodynamic conditions by

85 making the effect of the diffusive boundary layer (DBL) negligible. ${ }^{30}$ Uptake and pre- 
86 concentration is balanced with exposure time to yield sufficient time-intergated mass of analytes(s)

87 for detection. ${ }^{25}$

88 The principle of DGT is based on Fick's first law, ${ }^{25}$ such that the DGT measured-concentration

$89\left(C_{\mathrm{DGT}}\right)$ of target chemicals in solution can be calculated using Equation 1:

$$
\mathrm{C}_{\mathrm{DGT}}=\frac{\mathrm{M}(\Delta \mathrm{g}+\delta)}{\mathrm{D}_{e} \mathrm{At}}
$$

91 where, $M$ is the mass of analyte accumulated in the binding gel, $t$ is the exposure time, $D_{\mathrm{e}}$ is the

92 diffusion coefficient of the analyte in the diffusive layer, $A$ represents the sampling area of DGT,

$93 \Delta g$ is the diffused length through which the analyte passes before being taken up by the binding

94 phase, and $\delta$ is the thickness of the diffusive boundary layer (DBL).

95 There is great potential for applications of DGT to organic chemicals, but the first application to 96 organic compounds was not until 2012 by Chen et al. ${ }^{23}$ They investigated the performance 97 characteristics of DGT for quantifying polar organic compounds (with $\log K_{\text {ow }}$ value $<4$ ). The 98 newly developed DGT for organics was applied in rivers, wastewater treatment plants and soils to 99 sample antibiotics with XAD18 as the binding gel. ${ }^{31,} 32$ Zheng et al. ${ }^{33}$ subsequently applied 100 activated charcoal as the binding layer for DGT to detect bisphenols (BPs) in the aquatic 101 environment. Fauvelle et al. ${ }^{34}$ extended the application of DGT to glyphosate (PMG) and amino 102 methyl phosphonic acid (AMPA) using titanium dioxide (TiO2) as the binding layer. Weng et al. 103 explored the bioavailability of glyphosate in soils using DGT. ${ }^{35}$ Recently, more research has been 104 carried out developing DGT techniques for household and personal care products, illicit drugs, 105 organophosphorus flame retardants and pesticides. ${ }^{36-40}$ Although there are two publications ${ }^{36,38}$ on

106 DGT measurements for pesticides, the technique has not been developed for many important and 107 widely-used pesticides nor solved some essential technical issues, notably the choice of filter 108 membrane, diffusive and resin gels. DGT devices in these two recent papers were deployed 
109 without a filter membrane, probably due to significant adsorption of the target chemicals on to the

110 filter, which can affect the accuracy of the measurements. However, there is little use for a DGT

111 sampler without a filter membrane, as the hydrogel must be protected and cannot be directly

112 exposed in waters and soils, otherwise particulates/microbes may become embedded in it. ${ }^{41}$

113 The aim of this study was to develop the DGT technique to measure the available concentration of

114 a wide range of pesticides in waters and soils. In evaluating the performance characteristics of the

115 new DGT device, 9 pesticides were selected as test chemicals and two kinds of binding material

116 were tested. The binding kinetics and capacity of the binding gels were determined, and the effects

117 of deployment time, diffusive gel thickness, $\mathrm{pH}$, ionic strength, and organic matter were studied.

118 A field study deploying DGT in waters and the application of DGT in a defined soil:water ratio

119 were also undertaken to demonstrate the performance and applicability of the technique.

120 The 9 target chemicals were selected from various pesticides in use in the UK and China and

121 chosen to cover a range of different classifications (pesticides, insecticides and fungicides) and

122 different functional groups (detailed properties are listed in Table S1). They represent most of the

123 classes of polar pesticides in use. ${ }^{42}$ The method was also tested for some of the metabolites of

124 atrazine, to demonstrate its utility for fate studies.MATERIALS AND METHODS

125 Chemicals and reagents

126 High purity ( $\geq 98.5 \%$ ) standards of the 9 pesticides (pyrimethanil (PYR), ethofumesate (ETH),

127 fluometuron (FLU), chloridazon (CHL), clomazone (CLO), thiabendazole (THI), atrazine (ATR),

128 linuron (LIN) and pirimicarb (PIR)), atrazine metabolites (hydroxyatrazine (HA), deethylatrazine

129 (DEA), desisopropylatrazine (DIA), diaminochlorotriazine (DACT), cyanuricacid (CYA)) and 2

130 internal standards (atrazine-d5 and linuron-d6) were purchased from Sigma-Aldrich or Dr.

131 Ehrenstorfer. The details of the 9 target compounds are listed in Table S1, including their 
132 classification, use and some of their physicochemical properties. Two different materials -

133 Amberlite ${ }^{\mathrm{TM}}$ XAD 18 (Rohm and Haas Company) and Oasis HLB (Waters, UK) were used as

134 binding material. Details of the chemicals, reagents and materials are given in the Supporting

135 Information (SI).

136 Gel preparation and DGT assemblies

137 Polyacrylamide resin gels were made by mixing $4 \mathrm{~g}$ HLB binding resin or $1.5 \mathrm{~g}$ XAD18 binding 138 resins (wet weight), $10 \mathrm{~mL}$ gel solution (made by appropriate amounts of acrylamide solution, 139 cross-linker and MQ water), $60 \mu \mathrm{L}$ of ammonium persulphate and $15 \mu \mathrm{L}$ of TEMED (N,N,N',N'-

140 Tetramethylethylenediamine). The solutions were then pipetted between two glass plates separated

141 by spacers with a certain thickness and allowed to set at $42-45{ }^{\circ} \mathrm{C}$ for about 45 min. ${ }^{23,25,43}$

142 Agarose diffusive gel (containing 1.5\% agarose) was prepared by dissolving an appropriate

143 amount of agarose in an appropriate volume of pre-heated MQ water in a boiling water bath until

144 all the agarose was dissolved and the solution became transparent. The hot gel solution was

145 immediately pipetted into a preheated, gel-casting assembly and left to cool down to room

146 temperature. ${ }^{23}$ All gels were hydrated in MQ water and stored in $0.01 \mathrm{M} \mathrm{NaCl}$ solution. The DGT

147 device was assembled using the standard plastic base housing consisting of a base and a cap, ${ }^{30}$

148 the diffusive gel was sandwiched between the binding gel and a filter membrane.

149 Adsorption by DGT holder, filter membranes and diffusive gels

150 All materials used for DGT devices were assessed for possible adsorption of the target compounds.

151 Plastic DGT holders (piston and cap) (rinsed with methanol, followed by MQ water), 152 polyacrylamide gels (PA), agarose gels (AG), 6 different filter membranes obtained from 153 Whatman ${ }^{\circledR}$ (UK) (polyethenesulfone membrane, PES; nucleopore track-etch membrane, PC; 154 nylon membrane, NL; Cellulose Acetate membrane, OE; mixed celluse ester membrane, ME; 
155 hydrophilic polypropylene membrane, GHP) were exposed to $50 \mu \mathrm{g} \mathrm{L}^{-1}$ of the mixture of 156 compounds in $10 \mathrm{~mL}$ solutions (DGT holders were in $100 \mathrm{~mL}$ solution). They were shaken for 20 $157 \mathrm{~h}$ (Orbital, DOS-20L, Sky Line, ELMI). All materials were immersed in MQ water as blanks and 158 the pesticides solution alone served as controls. The concentrations in the solution before and after 159 experiment were measured to obtain the mass adsorbed.

\section{Binding capacity and uptake kinetics of resin gels}

161 To measure the binding capacity of the resin gels for accumulating the target pesticides, the resin 162 gel disc was immersed for $21 \mathrm{~h}$ in well-stirred solutions containing $0.01 \mathrm{M} \mathrm{NaCl}$ and a range of 163 concentrations of mixed compounds $\left(1,2,4,6,8,10 \mathrm{mg} \mathrm{L}^{-1}\right)$.

164 The resin gel disc was immersed in $40 \mathrm{~mL}$ of $200 \mu \mathrm{g} \mathrm{L}^{-1}$ mixed compounds solution with a matrix 165 of $0.01 \mathrm{M} \mathrm{NaCl}$ and shaken for $33 \mathrm{~h}$. Samples were taken out at various times from $5 \mathrm{~min}$ to $33 \mathrm{~h}$ 166 to measure the sorption kinetics of target compounds on two types of resin gels.

\section{Diffusion coefficient measurements}

168 The diffusion coefficients of the pesticides were measured using a diffusion cell that has been

169 reported previously. ${ }^{43}$ It comprises two compartments, each with an interconnecting $1.5 \mathrm{~cm}$ 170 diameter connecting window. A $2.5 \mathrm{~cm}$ diameter disc of $1 \mathrm{~mm}$ thick diffusive gel was placed 171 between the windows and the whole assembly clamped together. Both compartments were rinsed 172 with methanol and subsequently MQ water. The source compartment contained $100 \mathrm{~mL}$ of $1 \mathrm{mg}$ $173 \mathrm{~L}^{-1}$ mixed pesticides in $0.01 \mathrm{M} \mathrm{NaCl}$ solution; $100 \mathrm{~mL}$ of $0.01 \mathrm{M} \mathrm{NaCl}$ only solution was 174 introduced into the other compartment as the receptor solution. The water levels in both 175 compartments were exactly the same to ensure no difference in hydrostatic-head pressure. Both 176 compartments were stirred continuously using an overhead stirrer. Sub-samples of $0.2 \mathrm{~mL}$ were 
177 taken from each compartment at various intervals. The temperature during the experiment was $178 \quad 21.5 \pm 1.6^{\circ} \mathrm{C}$.

179 The slope of the linear plot of the mass of the measured chemical compound which diffused into 180 the receptor compartment versus time was used to calculate $D_{\mathrm{e}}$

$$
\mathrm{D}_{\mathrm{e}}=\frac{\text { slope } \times \Delta \mathrm{g}}{\mathrm{C}_{\mathrm{s}} \times \mathrm{A}_{\mathrm{s}}}
$$

182 where $\Delta \mathrm{g}$ is the thickness of the diffusive gel; $C_{\mathrm{s}}$ is the concentration of compounds in the source

183 compartment; and $A_{\mathrm{s}}$ is the area of the connecting window of the diffusion cell.

\section{Time dependence}

185 The DGT devices with both binding layers were deployed in $10 \mu \mathrm{g} \mathrm{L}^{-1}$ mixed pesticides solution $186\left(0.01 \mathrm{M} \mathrm{NaCl}, \mathrm{pH} 6.9 \pm 0.2\right.$, Temperature $\left.24 \pm 2{ }^{\circ} \mathrm{C}\right)$ for different time periods up to $84 \mathrm{~h}$. The

187 devices were on a floating holder, and the solution was stirred by a magnetic bar.

188 Diffusive layer thickness dependence

189 DGTs with HLB binding gel and containing diffusive gel of different thicknesses (0.5 to $1.5 \mathrm{~mm}$ )

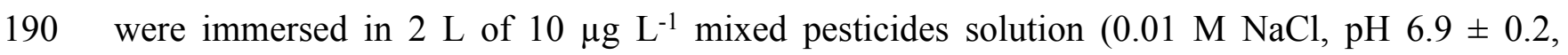
191 Temperature $21 \pm 2^{\circ} \mathrm{C}$ ) for $15 \mathrm{~h}$ to determine the relationship between mass accumulated by DGT 192 and diffusive gel thickness. All DGT test experiments were carried out in minimum 2 litre solutions 193 to prevent any significant depletion in concentration of the targeted chemicals.

\section{Effect of pH, ionic strength and DOM}

195 To investigate whether $\mathrm{pH}$ and ionic strength had any effect on DGT performance, DGT devices 196 were deployed in solutions of various $\mathrm{pH}$ and ionic strength. As the $\mathrm{pH}$ for natural water is 197 normally between 5 and 8, ${ }^{44,45}$ DGT devices were deployed in $2 \mathrm{~L}$ of $10 \mu \mathrm{g} \mathrm{L}^{-1}$ mixed pesticides 198 solution $(0.01 \mathrm{M} \mathrm{NaCl})$ of $\mathrm{pH}$ range from 4.7 to 8.2 for $17.8 \mathrm{~h}$ at $20 \pm 1^{\circ} \mathrm{C}$. For the effect of ionic 199 strength, DGT devices were exposed to $2 \mathrm{~L}$ of $10 \mu \mathrm{g} \mathrm{L}^{-1}$ mixed pesticides solution with $\mathrm{NaCl}$ 
200 ranging from 0.01 to $0.5 \mathrm{M}\left(\mathrm{pH} 6.9 \pm 0.2\right.$, temperature $20 \pm 2{ }^{\circ} \mathrm{C}$ ). Effects of DOM were tested by 201 deploying DGT devices in $2 \mathrm{~L}$ of $10 \mu \mathrm{g} \mathrm{L}-1$ mixed pesticides solution with DOM ranging from 0 $20220 \mathrm{mg} \mathrm{L}^{-1}\left(0.01 \mathrm{M} \mathrm{NaCl}, \mathrm{pH} 6.9 \pm 0.2\right.$, temperature $\left.21 \pm 1^{\circ} \mathrm{C}\right)$ for $16 \mathrm{~h}$.

\section{DGT extraction, analytical methods and detection limits}

204 After deployment, all the devices were rinsed with MQ water thoroughly before they were

205 disassembled. The diffusive gel was peeled off, and the binding gel was placed in a pre-cleaned 206 amber vial. $50 \mathrm{ng}$ of internal standards (ATR-d5 and LIN-d6) were added before extraction. Two 207 consecutive $5 \mathrm{~mL}$ portions of $\mathrm{MeOH}$ were added to the vial to extract target pesticides from the 208 binding gel by $30 \mathrm{~min}$ ultrasonic bath. The concentrations of the pesticides were then determined 209 following the procedure described below.

210 The separation of the target chemicals was performed with a Phenomenex Kinetex Biphenyl 211 column $(50 \times 2.1 \mathrm{~mm}, 2.6 \mu \mathrm{m})$. Liquid chromatography with mass spectrometry (LC-MS) was used

212 for laboratory samples of the 9 pesticides, with an Agilent LC coupled with a HP single quadrupole 213 mass spectrometer detector with an ESI interface. It is adequate as all the target chemicals were 214 added to laboratory testing solutions at reasonably high levels. Details of analysis are provided in 215 the SI. Field samples including atrazine metabolites were analysed on a Shimadzu Nexera X2 LC 216 coupled with a Shimadzu LCMS-8030 triple quadrupole mass spectrometer detector (details in 217 SI). 
218 The instrumental detection limits (IDLs) for LS-MS were calculated according to the

219 standard deviation from a measured concentration of standard (8 times) and method

220 detection limits (MDLs) were calculated based on IDLs, the recoveries for water samples and

221 DGT samples and the dilution factors. The results are given in Table 1 (details of the

222 calculation are shown in Table S3(a), Table S3(b) summarises the IDLs and MDLs of ATR

223 and its metabolites in water and soils samples for LC-MS/MS).DGT for pesticide metabolites

224 Verification of DGT measurement for pesticide metabolites was carried out in solution of $\mathrm{pH} 7$

225 and ionic strength $0.01 \mathrm{M}$ containing atrazine and its metabolites (HA, DEA, DIA, DACT, CYA).

226 DGT devices with HLB resin gel were deployed in the solution for 24 hours at $21 \pm 1^{\circ} \mathrm{C}$. After

227 deployment, the binding gel was extracted with $10 \mathrm{~mL}$ ACN by 30 min ultrasonic bath.

228 Field applications in waters and soils

229 A field trial was undertaken by deploying DGT devices in two sampling sites of the She River in

230 Fushun, China, for in situ measurement of pesticides. Each site had 3 sampling locations. DGT

231 devices were deployed in triplicate, $30 \mathrm{~cm}$ below the water surface for 4 and 7 days. Traditional

232 grab samples were also taken on day 4 and day 7 of the DGT deployment using 1 L amber bottles.

233 They were filtered and pre-concentrated using a well-established solid-phase extraction (SPE)

234 method. ${ }^{46}$ Detailed information is shown in the SI. At the end of the deployment, the DGT devices

235 were retrieved and rinsed with MQ water and then placed in clean plastic bags for transport. The

236 sample treatments and analysis were the same as the methods above.

237 To test the DGT applicability in soils, five soils of different properties collected from the UK and

238 China were spiked with ATR at the concentration of $100 \mathrm{mg} \mathrm{kg}^{-1}$. The deployment was carried out

239 after 23 days when ATR reached equilibrium between soil solution and the solid phase. Soils were

240 hydrated with MQ water to a fixed soil:water ratios ( $>80 \%$ of Maximum Water Holding Capacity) 
241 before deployment. The details of soil properties, soil collection and treatments, and DGT 242 deployment in soils are listed in SI and Table S5.

243 Quality assurance/control (QA/QC)

244 All DGT deployments in laboratory and field were carried out in triplicates and the results were 245 expressed as the average \pm standard deviation (SD). 3 DGT devices were retieved prior to each 246 deployment as blank samples. Control samples (test solution without DGT devices) were 247 performed in each experiment to prevent the possible interference during the experiment. All the 248 SPE samples were replicated, no target compounds were found in the blank SPE samples.

\section{RESULTS AND DISCUSSION}

\section{Sorption by DGT holder, filter membrane and diffusive gels}

251 There was no appreciable sorption of target compounds on the two types of diffusive gels or DGT 252 mouldings as shown in Figure S1(a). However, compounds were sorbed substantially by PES, NL, 253 OE and ME filter membranes (Figure S1(b)). Sorption to the PES filters was marked (>50\%) 254 this filter type has been used for POCIS ${ }^{16}$ and Chemcatcher; ${ }^{19}$ loss on the ME filter was also 255 considerable. The PES filters were also used in DGT devices for other medium polar chemicals in 256 other studies and the adsorption effect was negligible. PC and GHP showed little sorption of the 257 compounds; PC membrane performed the best, with $<5 \%$ for 5 compounds and $<15 \%$ for the other 258 four. It was therefore selected for the subsequent experiments.

259 The results on sorption to membranes/filters are important. Some studies have encountered 260 problems of retention of medium polarity compounds onto filters with DGT, leading them to 261 advocate that no filters be used. However, use of a filter is an intrinsic and key feature of DGT, 262 being needed to protect the gel from particle intrusion and to limit biofouling effects on uptake. A 
263 wide array of filter materials are available on the market and these can be screened/tested, to help

264 selection of the best type for different analytes.

265 Agarose gel (thickness of $1 \mathrm{~mm}$ ) was chosen as the diffusive gel as it is cheaper compared to the

266 polyacrylamide gel and easier to prepare.

267 Binding capacity of resin gels

268 DGT samplers are normally deployed in the environment to accumulate target compounds over 269 periods of weeks or more. Knowledge of the binding capacity of the resin gel is important, to help 270 determine optimum sampling times for accurate measurements. ${ }^{30}$ For the HLB binding gel, the 271 uptake masses of all 9 pesticides increased linearly with increasing concentration in the bulk 272 solutions (see Figure 1 and Figure S2). The binding capacity is dependent on the amount of resin 273 used. According to the test concentration, the capacity of these pesticides on the HLB gel disc was 274 at least within the range of 19-44 $\mu \mathrm{g}$ per disc (the lowest for CHL and the highest for PYR), 275 assuming only half of the resin would be available during DGT deployment (the other half 276 embedded deeper in the gel was not considered). If the devices are deployed for 2 weeks, from 277 equation 1 , the concentration of CHL that can be accurately measured (within the binding capacity) 278 would be at least $75 \mu \mathrm{g} \mathrm{L}^{-1}$ and that of PYR would be at least $200 \mu \mathrm{g} \mathrm{L}{ }^{-1}$. These are much higher 279 than reported environmental concentrations. ${ }^{47}$, 48 The amount of XAD18 which could be 280 incorporated in the gel solution of the standard DGT configuration was less than HLB resin. The 281 masses of pesticides bound to the XAD18 gel increased linearly with increasing solution 282 concentrations for all compounds except ATR and CHL. This could be caused by the competition 283 between the compounds. ${ }^{49}$ The mass of CHL did not increase with solution concentration, 284 indicating that there was no significant binding of CHL on the XAD18 resin. Although the binding 285 capacity of XAD18 gel is lower than HLB in the present configuration, it is still enough for at least 
2862 weeks deployment in a polluted environment. Increased capacity for longer sampling is easily

287 obtained by different configurations of DGT (e.g. by using smaller size of resin to increase the

288 specific surface area for binding). Caution needs to be taken when using the capacity values to

289 estimate the deployment time in the field. The above capacity measurements were carried out in

290 solutions of targeted pesticides only, without the presence of other competing chemicals. As it is

291 not practical to test all the competing chemicals for all the possible scenarios in the laboratory

292 condition, multiple deployment times should be carried out when DGT is used in an unknown

293 environment for the first time.

\section{Uptake kinetics of the resin gels}

295 To ensure fully quantitative measurement by DGT, it is crucial to have rapid uptake of the target

296 chemical by the resin gel, to create close to zero concentration at the resin gel/diffusive gel

297 interface. The uptake of target compounds by XAD18 gel increased sharply and linearly within 2

298 h (Figure 2 and Figure S3), then slowly increased up to 8 hours. After 8 hours interaction, 6

299 compounds were adsorbed by $>80 \%$ of the total amount added; most of the target chemicals (near

$300100 \%$ ) were adsorbed within $12 \mathrm{~h}$, showing the effective pre-concentration nature of the device.

301 The kinetics of the uptake by the HLB gel was slower than that of the XAD18 gel, but was still

302 completed within $24 \mathrm{~h}$. According to Fick's law of diffusion, the minimum uptake amount of target

303 pesticide by the resin gel is about $10 \mathrm{ng}$ at the first 5 minutes. The results presented in Figure 2

304 show minima of $99 \mathrm{ng}$ for all test chemicals and for both resin gels. The results show that the target

305 compounds bound onto these two types of gels sufficiently rapidly to ensure the concentration of

306 these compounds at the diffusive/ binding gel interface will be zero, which enables good

307 performance of DGT. 


\section{Diffusion coefficient measurement}

309 The diffusion coefficient of a targeted chemical, $D_{\mathrm{e}}$, is an essential parameter to calculate its

310 concentration, $C_{\text {DGT }}$, using Equation (1). It is measured independently using the diffusion cell. ${ }^{43}$

311 Based on the methods mentioned above, the diffusion coefficients of the 9 pesticides were 312 measured at $21.5^{\circ} \mathrm{C}$ and the standard diffusion coefficient at $25^{\circ} \mathrm{C}$ was obtained from Equation

\section{3 (3):}

$$
\log \mathrm{D}_{\mathrm{t}}=\frac{1.37023(\mathrm{t}-25)+\left(8.36 \times 10^{-4}\right)(\mathrm{t}-25)^{2}}{109+\mathrm{t}}+\log \frac{\mathrm{D}_{25}(273+\mathrm{t})}{298}
$$

315 The diffusion coefficient of the target compound at the solution temperature $t\left({ }^{\circ} \mathrm{C}\right)$ during the

316 diffusion cell experiment is $D_{t}$, and $D_{25}$ is the diffusion coefficient of the target compound at $25^{\circ} \mathrm{C}$.

317 The typical plots of mass diffused versus experiment time for the target pesticides in the diffusion 318 cell gave the slopes shown in Figure S4. All the data are shown in Table S4.

319 In order to compare with POCIS and Chemcatcher passive samplers, the sampling rate per unit 320 area for DGT was calculated using Equation (4). ${ }^{31}$

$$
\mathrm{R}_{\mathrm{S} / \mathrm{A}}=\frac{\mathrm{D}_{\mathrm{e}}}{\Delta \mathrm{g}}
$$

322 Table 2 shows that the $R_{\mathrm{S} / \mathrm{A}}$ values for the DGT sampler ranged from 0.76 to $32.7 \mathrm{~mL}\left(\mathrm{~d} \mathrm{~cm}^{2}\right)^{-1}$.

323 For THI, ATR and LIN, the $R_{\mathrm{S} / \mathrm{A}}$ values for DGT were comparable with $R_{\mathrm{S} / \mathrm{A}}$ values reported in the

324 literature for POCIS and Chemcatcher.

\section{Effect of deployment time and diffusive gel thickness}

326 Two experiments, testing the relationships of accumulated mass versus deployment time and

327 diffusion layer thickness, were carried out to validate the principle of DGT for measuring 328 pesticides. The masses of targeted chemicals accumulated by DGT increased linearly (for 7

329 chemicals sorbed by HLB and 5 chemicals with XAD18, R ${ }^{2}$ values were higher than 0.99 ) with 330 time up to $87 \mathrm{~h}$ and agreed well with the theoretical line calculated by Equation (1) for most 
331 chemicals (see Figure S5). For DGT devices with HLB resin gel, the results for ETH showed

332 significant deviation from the theoretical line after deployment for 36 hours. For devices with

333 XAD resin gel, only three target chemicals, ATR, THI and CLO, followed the theoretical line. The

334 other six chemicals showed different degrees of deviation at different deployment times. These

335 results indicate that the performance of DGT with HLB is better than that with XAD18 gel for

336 measuring pesticides. A further test of the DGT principle for pesticides was carried out using HLB

337 DGT devices with different thicknesses of diffusive gel in a well stirred solution. The measured

338 mass of the target compounds that diffused through the diffusive gel layer was inversely

339 proportional to the diffusion layer thickness (Figure S6). The experimental data agreed well with

340 the theoretical line obtained from the Equation (1). Both results of time dependence and diffusion

341 layer thickness confirm the principle and mechanism of the DGT technique for pesticides in

342 solution.

343 The results obtained from the different diffusion layer thicknesses also indicate the DBL at the

344 surface of the device is insignificant during the experiment under stirred conditions and it can be

345 neglected in calculations.

\section{Effect of pH, ionic strength and DOM}

347 Pesticides can be neutral, cationic, anionic or zwitterionic, depending on the $\mathrm{pH}$ of the solution.

348 Their physicochemical properties may change with the environmental conditions, which can also

349 affect the performance of DGT. It is therefore important to confirm that uptake to DGT is

350 independent of the normal range of environmental variables.

351 To assess the $\mathrm{pH}$ effect on the DGT measurement, DGT devices were immersed in solutions with

352 the $\mathrm{pH}$ ranged from 4.7 to 8.2 . The ratio of the target compound concentrations measured by DGT

$353\left(C_{\mathrm{DGT}}\right)$ to their concentrations in the bulk solutions $\left(C_{\mathrm{b}}\right)$ were plotted against $\mathrm{pH}$ values (Figure 
354 S7). The results indicate that $\mathrm{pH}$ of the solution had no marked effect on the measurement by DGT 355 with HLB binding gel as most of the ratios $\left(C_{\mathrm{DGT}} / C_{\mathrm{b}}\right)$ were between 0.9 and 1.1 . However, for 356 DGT with XAD18 binding gel, the $C_{\mathrm{DGT}} / C_{\mathrm{b}}$ ratios were below 0.9 at $\mathrm{pH} 7$ for all tested compounds 357 and at $\mathrm{pH} 6$ and 7.5 for most compounds. This could be due to less efficient and less effective 358 uptake of chemicals by XAD resin at more neutral $\mathrm{pH}$ range. These results demonstrate that DGT 359 with HLB binding gel can accurately measure concentrations of pesticides in the aquatic 360 environment with a wide range of $\mathrm{pH}$, whereas DGT with XAD 18 binding gel has its limitations.

361 The effect of IS on DGT measurements was investigated in solutions with ionic strength similar 362 to freshwater, estuary water and seawater, ranging from $0.01 \mathrm{M}$ to $0.5 \mathrm{M}$. For DGT with HLB 363 binding gel, there was no significant effect observed in the range of $0.01 \mathrm{M}$ to $0.25 \mathrm{M}$, as shown 364 in Figure S8. The ratios of $C_{\mathrm{DGT}}$ to $C_{\mathrm{b}}$ were within 0.9 and 1.1 for all tested chemicals. At the IS 365 of $0.5 \mathrm{M}$ (close to seawater), the DGT measured concentrations were slightly lower than expected. 366 The ratio of $C_{\mathrm{DGT}}$ to $C_{\mathrm{b}}$ was $<0.9$ for ATR, THI and CLO, and close to 0.9 for other six chemicals.

367 The viscosity of the solution is higher on addition of a large amount of $\mathrm{NaCl}$, which impedes the 368 mass transfer process. ${ }^{50}$

369 The effect of DOM on measurements of target chemicals by DGT devices with HLB resin as 370 binding phase is demonstrated in Figure $\mathrm{S} 9$. The ratios of $C_{\mathrm{DGT}} / C_{\mathrm{b}}$ were between 0.9 and 1.1 for 371 majority of the chemicals at various DOM concentrations up to $20 \mathrm{mg} \mathrm{L}^{-1}$. The $C_{\mathrm{DGT}} / C_{\mathrm{b}}$ ratios of 372 some chemicals, such as CHL, FLU, PIR and CLO were $<0.9$, but similar to the ratios for the 373 control solution where the DOM concentration was zero. These findings suggest that the 374 performance of DGT is independent of DOM concentration. Similar phenomena have been 375 observed in the study of Li et al. ${ }^{51}$ using POCIS for pharmaceuticals and personal care products 
376 (PPCPs) and endocrine disrupting chemicals (EDCs), where $R_{\mathrm{s}}$ was not affected by DOM. Li et

377 al.'s research on perfluorinated chemicals has also shown similar results. ${ }^{52}$

378 In general, the performance of DGT devices with HLB resin gel was better than the DGT devices

379 with XAD18 resin as the binding gel. DGT with HLB resin gel was therefore selected as suitable

380 for the future experiments and measurements.

381 DGT for atrazine metabolites

382 All the metabolites except CYA were detected and measured quantitatively by DGT devices. CYA 383 could be taken up by DGT with HLB binding gel, but could not be eluted effectively from the

384 HLB resin using the present elution reagents. The results are expressed as the ratio of the DGT 385 measured concentration $\left(C_{\mathrm{DGT}}\right)$ and the concentration in solution by conventional method $\left(C_{\mathrm{b}}\right)$ 386 (Figure S10). The ratios for all compounds were between 0.9 and 1.1 and most of them were close

387 to 1.0. The results indicate that DGT can be used for measuring not only the pesticides, but also 388 metabolites. This opens up important opportunities for detailed fate studies.

389 Field applications in waters and soils

$390 \quad$ In situ DGT deployments in river water

391 The results of DGT deployments in the She River and Dahuofang Reservoir, north China are

392 presented in Figure 3. ATR was the only detectable target compound in both grab samples and in 393 DGT samplers.

394 DGT provides TWA concentrations of ATR over the exposure period. The similar concentrations 395 in the 3 locations of the river (Figure 3a) between two different deployment periods, 4 days and 7 396 days, indicate: i) the concentration of ATR during the 7 days was consistent without significant 397 variation; ii) the distribution of ATR in the 3 locations (about 50 meters apart) was similar and iii) 398 DGT performance was good during the long deployment period and not affected by environmental 
399 factors, such as biofouling. The deployment time could be extended longer as the DGT device has

400 a great capacity for all the targeted chemicals. However, the common problems for all passive 401 samplers such as biofouling and possible degradations may affect the accuracy of the 402 measurements for longer time deployments. As the river water flow was fast, the DBL was 403 neglected in calculating $C_{\text {DGT }}$ as the DBL thickness was estimated to be much smaller than the 404 thickness of the diffusive gel. Deployment in the reservoir showed slightly greater variation in 405 DGT measured concentrations of ATR between three different locations and between two different 406 deployment times (Figure 3b), notably for locations L5 and L6. This is reasonable as the mixing 407 in the reservoir may be less efficient compared to the river. The concentrations of ATR in grab 408 samples were higher than DGT measured in situ concentrations. Although the differences were 409 small, relative to the measurements made and the techniques used, DGT usually gives lower values 410 than bulk water smpling because DGT only measures the available fraction which is dissolved and 411 able to diffuse through the diffusive gel. The measurement from the grab samples gives the total 412 concentration, including colloids and complexed fractions that may not be measured by DGT.

413 Several studies have also shown the advantage of DGT over grab sampling when measuring 414 chemical concentration in a changing environment. ${ }^{27,53}$

\section{DGT measurements in soils}

416 DGT devices were deployed in five different soils after wetting with water (Table S5) to test the 417 applicability of the technique for measuring pesticides and their metabolites in soils. ATR and it 418 metabolites were chosen as test compounds. The results are shown in Table 3. HA and DEA were 419 the primary metabolites measured and DIA and DACT were not detected in these soils, the 420 concentration of HA was much higher than that of DEA, indicating that the chemical degradation 421 pathway was favoured, rather than biological degradation., Although CYA was detected in soil F, 
422 the result was not presented here since CYA could not be eluted efficiently from HLB resin in the

423 DGT performance test experiment. The extremely low concentration of ATR in soil F indicates

424 the fast degradation of ATR in that soil. Soil F was collected from highly productive agricultural

425 land with regular addition of fertilisers and pesticides; this is likely to make the microbial activity

426 much higher than in the other test soils, ${ }^{54,55}$ and therefore with much faster ATR degradation.

427 Although ATR was spiked to the same total concentration for all the soils, DGT measured 428 concentrations, $C_{\mathrm{DGT}}$, varied between soils. The available ATR concentrations in soils M and D

429 were similar, but less than concentrations in soils $\mathrm{R}$ and $\mathrm{K}$. This is likely due to much lower $\mathrm{pH}$ in 430 soils $\mathrm{M}$ and $\mathrm{D}$, since adsorption of ATR to soil increases at lower $\mathrm{pH} .{ }^{56}$ The concentrations of 431 metabolites in soils $\mathrm{M}$ and $\mathrm{D}$ were greater than those in soils $\mathrm{R}$ and $\mathrm{K}$, consistent with findings by 432 other researchers that hydrolysis of ATR decreases with increasing soil $\mathrm{pH} .{ }^{57}$ Although organic 433 matter content enhanceddegradation of ATR, ${ }^{13} \mathrm{pH}$ seemed to have more influence due to the big 434 range in $\mathrm{pH}$ in those soils.

\section{CONCLUSIONS}

436 A novel DGT sampling technique on measurement for 9 pesticides has been successfully

437 developed through systematic performance tests, HLB resin was selected as binding agent and 438 agarose as diffusive gel. The DGT sampler can provide comparable sampling rate per unit area $439\left(R_{\mathrm{S} / \mathrm{A}}\right)$ to other passive samplers. The measurement of these pesticides using DGT was independent 440 of $\mathrm{pH} 4.7-8.2$, ionic strength $0.01-0.25 \mathrm{M}$, and DOM up to $20 \mathrm{mg} \mathrm{L}^{-1}$, extending its utility for a 441 wide range of environmental conditions. It is capable of measuring pesticide metabolites, implying 442 its potential of exploring the environmental fate and behaviour of organic chemicals. It has also 443 been assessed under field conditions. This study has demonstrated that DGT sampler with HLB 
444 resin gel is a reliable technique for in situ measurement of several groups of pesticides in waters

445 and soils.

SUPPORTING INFORMATION

447 Information on analytical method, sampling sites, supplementary tables and figures. This material

448 is available free of charge via the Internet at http://pub s.acs.org.

\section{AUTHOR INFORMATION}

450 Corresponding author

451 *E-mail: h.zhang@lancaster.ac.uk; Tel: +44 1524593899.

452 k.c.jones@1ancaster.ac.uk; Tel: +44 1524510230

\section{ACKNOWLEDGEMENT}

454 The authors thank Dr. Hao Cheng for assistance in making gels, Dr. Shane Rothwell for assistance 455 in soil sampling, and Mr. Chunlong Xia and Mr. Puyu Xi for helping in water sampling. We are 456 grateful to the Chinese Scholarship Council (CSC) for sponsorship of Yanying Li.

\section{REFERENCES}

458 1. Huang, P. M.; Iskandar, I. K., Soils and Groundwater Pollution and Remediation: Asia, 459 Africa, and Oceania. CRC Press: Florida, 1999.

460 2. Rial Otero, R.; Cancho Grande, B.; Arias Estévez, M.; López Periago, E.; Simal Gándara, 461 J., Procedure for the measurement of soil inputs of plant-protection agents washed off through 462 vineyard canopy by rainfall. Journal of agricultural and food chemistry 2003, 51 (17), 5041-5046. 463 3. Pimentel, D.; Levitan, L., Pesticides: amounts applied and amounts reaching pests. 464 Bioscience 1986, 36 (2), 86-91.

4654 4. Pimentel, D., Amounts of pesticides reaching target pests: environmental impacts and 466 ethics. Journal of Agricultural and Environmental Ethics 1995, 8 (1), 17-29.

467 5. van der Werf, H. M., Assessing the impact of pesticides on the environment. Agriculture, 468 Ecosystems \& Environment 1996, 60 (2-3), 81-96.

469 6. Ingram, C.; Coyne, M. S.; Williams, D. W., Effects of commercial diazinon and 470 imidacloprid on microbial urease activity in soil and sod. Journal of Environmental Quality 2005, $47134(5), 1573-1580$.

$4727 . \quad$ Littlefield-Wyer, J. G.; Brooks, P.; Katouli, M., Application of biochemical fingerprinting 473 and fatty acid methyl ester profiling to assess the effect of the pesticide Atradex on aquatic 474 microbial communities. Environmental Pollution 2008, 153 (2), 393-400. 
475 8. Hussain, S.; Siddique, T.; Saleem, M.; Arshad, M.; Khalid, A.; Sparks, D., Impact of 476 Pesticides on Soil Microbial Diversity, Enzymes, and Biochemical Reactions. Advances in 477 Agronomy, Vol 102 2009, 102, 159-200.

478 9. Margni, M.; Rossier, D.; Crettaz, P.; Jolliet, O., Life cycle impact assessment of pesticides 479 on human health and ecosystems. Agriculture, Ecosystems \& Environment 2002, 93 (1), 379-392.

480 10. Malik, A.; Grohmann, E.; Akhtar, R., Environmental Deterioration and Human Health: 481 Natural and Anthropogenic Determinants. Springer Science \& Business Media: 2013.

482 11. Tadeo, J. L., Analysis of Pesticides in Food and Environmental Samples. CRC Press: Boca 483 Raton, 2008.

484 12. Sun, L.; Lee, H. K., Optimization of microwave-assisted extraction and supercritical fluid 485 extraction of carbamate pesticides in soil by experimental design methodology. Journal of 486 Chromatography A 2003, 1014 (1), 165-177.

487 13. Gavrilescu, M., Fate of pesticides in the environment and its bioremediation. Engineering 488 in Life Sciences 2005, 5 (6), 497-526.

489 14. MacLeod, S. L.; McClure, E. L.; Wong, C. S., Laboratory calibration and field deployment 490 of the polar organic chemical integrative sampler for pharmaceuticals and personal care products 491 in wastewater and surface water. Environmental Toxicology and Chemistry 2007, 26 (12), $2517-$ 4922529.

493 15. Kingston, J. K.; Greenwood, R.; Mills, G. A.; Morrison, G. M.; Persson, L. B., 494 Development of a novel passive sampling system for the time-averaged measurement of a range of organic pollutants in aquatic environments. Journal of Environmental Monitoring 2000, 2 (5), 487-495.

16. Alvarez, D. A.; Petty, J. D.; Huckins, J. N.; Jones - Lepp, T. L.; Getting, D. T.; Goddard, J. P.; Manahan, S. E., Development of a passive, in situ, integrative sampler for hydrophilic organic contaminants in aquatic environments. Environmental Toxicology and Chemistry 2004, 23 (7), 1640-1648.

501 17. Morin, N.; Miège, C.; Coquery, M.; Randon, J., Chemical calibration, performance, validation and applications of the polar organic chemical integrative sampler (POCIS) in aquatic environments. TrAC Trends in Analytical Chemistry 2012, 36, 144-175. 18. Ibrahim, I.; Togola, A.; Gonzalez, C., Polar organic chemical integrative sampler (POCIS) uptake rates for 17 polar pesticides and degradation products: laboratory calibration. Environmental Science and Pollution Research 2013, 20 (6), 3679-3687.

19. Schäfer, R. B.; Paschke, A.; Vrana, B.; Mueller, R.; Liess, M., Performance of the Chemcatcher $^{\circledR}$ passive sampler when used to monitor 10 polar and semi-polar pesticides in 16 Central European streams, and comparison with two other sampling methods. Water Research 2008, 42 (10), 2707-2717.

20. Cristale, J.; Katsoyiannis, A.; Chen, C.; Jones, K.; Lacorte, S., Assessment of flame retardants in river water using a ceramic dosimeter passive sampler. Environmental Pollution 2013, 172, 163-169.

514 21. Fauvelle, V.; Montero, N.; Mueller, J.; Banks, A.; Mazzella, N.; Kaserzon, S., Glyphosate and AMPA passive sampling in freshwater using a microporous polyethylene diffusion sampler. Chemosphere 2017, 188, 241-248.

518 Measurement of environmental pollutants using passive sampling devices-an updated 519 commentary on the current state of the art. Environmental Science: Processes \& Impacts 2014, 16 520 (3), 369-373. 
23. Chen, C.-E.; Zhang, H.; Jones, K. C., A novel passive water sampler for in situ sampling of antibiotics. Journal of Environmental Monitoring 2012, 14 (6), 1523-1530.

24. Luo, J.; Cheng, H.; Ren, J.; Davison, W.; Zhang, H., Mechanistic insights from DGT and soil solution measurements on the uptake of $\mathrm{Ni}$ and $\mathrm{Cd}$ by radish. Environmental Science \& Technology 2014, 48 (13), 7305-7313.

25. Davlson, W.; Zhang, H., In situspeciation measurements of trace components in natural waters using thin-film gels. Nature 1994, 367 (6463), 546-548.

26. Denney, S.; Sherwood, J.; Leyden, J., In situ measurements of labile $\mathrm{Cu}, \mathrm{Cd}$ and $\mathrm{Mn}$ in river waters using DGT. Science of the Total Environment 1999, 239 (1-3), 71-80.

27. Dunn, R.; Teasdale, P.; Warnken, J.; Jordan, M.; Arthur, J., Evaluation of the in situ, timeintegrated DGT technique by monitoring changes in heavy metal concentrations in estuarine waters. Environmental Pollution 2007, 148 (1), 213-220.

28. Zhang, H.; Davison, W.; Knight, B.; McGrath, S., In situ measurements of solution concentrations and fluxes of trace metals in soils using DGT. Environmental Science \& Technology 1998, 32 (5), 704-710.

29. Harper, M. P.; Davison, W.; Zhang, H.; Tych, W., Kinetics of metal exchange between solids and solutions in sediments and soils interpreted from DGT measured fluxes. Geochimica et Cosmochimica Acta 1998, 62 (16), 2757-2770.

30. Zhang, H.; Davison, W., Performance characteristics of diffusion gradients in thin films for the in situ measurement of trace metals in aqueous solution. Analytical Chemistry 1995, 67 (19), 3391-3400.

31. Chen, C.-E.; Zhang, H.; Ying, G.-G.; Jones, K. C., Evidence and recommendations to support the use of a novel passive water sampler to quantify antibiotics in wastewaters. Environmental Science \& Technology 2013, 47 (23), 13587-13593.

32. Chen, C.; Chen, W.; Ying, G.; Jones, K.; Zhang, H., In situ measurement of solution concentrations and fluxes of sulfonamides and trimethoprim antibiotics in soils using o-DGT. Talanta 2015, 132, 902-908.

33. Zheng, J.-L.; Guan, D.-X.; Luo, J.; Zhang, H.; Davison, W.; Cui, X.-Y.; Wang, L.-H.; Ma, L. Q., Activated charcoal based diffusive gradients in thin films for in situ monitoring of bisphenols in waters. Analytical Chemistry 2014, 87 (1), 801-807.

34. Fauvelle, V.; Nhu-Trang, T.-T.; Feret, T.; Madarassou, K.; Randon, J. r. m.; Mazzella, N., Evaluation of titanium dioxide as a binding phase for the passive sampling of glyphosate and aminomethyl phosphonic acid in an aquatic environment. Analytical Chemistry 2015, 87 (12), 6004-6009.

35. Weng, Z.; Rose, M. T.; Tavakkoli, E.; Van Zwieten, L.; Styles, G.; Bennett, W.; Lombi, E., Assessing plant-available glyphosate in contrasting soils by diffusive gradient in thin-films technique (DGT). Science of The Total Environment 2019, 646, 735-744.

36. Challis, J. K.; Hanson, M. L.; Wong, C. S., Development and calibration of an organicdiffusive gradients in thin films aquatic passive sampler for a diverse suite of polar organic contaminants. Analytical Chemistry 2016, 88 (21), 10583-10591.

37. Guo, C.; Zhang, T.; Hou, S.; Lv, J.; Zhang, Y.; Wu, F.; Hua, Z.; Meng, W.; Zhang, H.; Xu, J., Investigation and application of a new passive sampling technique for in situ monitoring of illicit drugs in waste waters and rivers. Environmental Science \& Technology 2017, 51 (16), 91019108. 
38. Guibal, R.; Buzier, R.; Charriau, A.; Lissalde, S.; Guibaud, G., Passive sampling of anionic pesticides using the Diffusive Gradients in Thin films technique (DGT). Analytica Chimica Acta 2017, 966, 1-10.

39. Chen, W.; Li, Y.; Chen, C.; Sweetman, A.; Zhang, H.; Jones, K., DGT passive sampling for quantitative in situ measurements of compounds from household and personal care products in waters. Environmental Science \& Technology 2017, 51 (22), 13274-13281.

40. Zou, Y.-T.; Fang, Z.; Li, Y.; Wang, R.; Zhang, H.; Jones, K. C.; Cui, X.-Y.; Shi, X.-Y.; Yin, D.; Li, C., Novel Method for in Situ Monitoring of Organophosphorus Flame Retardants in Waters. Analytical chemistry 2018, 90 (16), 10016-10023.

41. Chang, L.-Y.; Davison, W.; Zhang, H.; Kelly, M., Performance characteristics for the measurement of Cs and Sr by diffusive gradients in thin films (DGT). Analytica chimica acta 1998, 368 (3), 243-253.

42. Marrs, T. T.; Ballantyne, B., Pesticide Toxicology and International Regulation. John Wiley \& Sons: 2004.

43. Zhang, H.; Davison, W., Diffusional characteristics of hydrogels used in DGT and DET techniques. Analytica Chimica Acta 1999, 398 (2), 329-340.

44. Chester, R., Marine geochemistry. Blackwell Science: 2009.

45. Hahn, H. H.; Hoffmann, E.; Ødegaard, H., Chemical Water and Wastewater Treatment IX. IWA publishing: UK, 2007.

46. Loos, R.; Locoro, G.; Contini, S., Occurrence of polar organic contaminants in the dissolved water phase of the Danube River and its major tributaries using SPE-LC-MS ${ }^{2}$ analysis. Water Research 2010, 44 (7), 2325-2335.

47. Berenzen, N.; Lentzen-Godding, A.; Probst, M.; Schulz, H.; Schulz, R.; Liess, M., A comparison of predicted and measured levels of runoff-related pesticide concentrations in small lowland streams on a landscape level. Chemosphere 2005, 58 (5), 683-691.

48. Seeland, A.; Albrand, J.; Oehlmann, J.; Muller, R., Life stage-specific effects of the fungicide pyrimethanil and temperature on the snail Physella acuta (Draparnaud, 1805) disclose the pitfalls for the aquatic risk assessment under global climate change. Environmental Pollution 2013, 174, 1-9.

49. Li, Q.; Snoeyink, V.; Mariaas, B.; Campos, C., Elucidating competitive adsorption mechanisms of atrazine and NOM using model compounds. Water Research 2003, 37 (4), 773 784.

50. Castells, P.; Santos, F.; Galceran, M., Solid-phase microextraction for the analysis of shortchain chlorinated paraffins in water samples. Journal of Chromatography A 2003, 984 (1), 1-8.

51. Li, H.; Helm, P. A.; Paterson, G.; Metcalfe, C. D., The effects of dissolved organic matter and $\mathrm{pH}$ on sampling rates for polar organic chemical integrative samplers (POCIS). Chemosphere 2011, 83 (3), 271-280.

52. Li, Y.; Yang, C.; Bao, Y.; Ma, X.; Lu, G., Aquatic passive sampling of perfluorinated chemicals with polar organic chemical integrative sampler and environmental factors affecting sampling rate. Environmental Science and Pollution Research 2016, 23 (16), 16096-16103.

53. Allan, I.; Knutsson, J.; Guigues, N.; Mills, G.; Fouillac, A.; Greenwood, R., Evaluation of the Chemcatcher and DGT passive samplers for monitoring metals with highly fluctuating water concentrations. Journal of Environmental Monitoring 2007, 9 (7), 672-681.

54. Haynes, R.; Naidu, R., Influence of lime, fertilizer and manure applications on soil organic matter content and soil physical conditions: a review. Nutrient Cycling in Agroecosystems 1998, $51(2), 123-137$. 
611 55. Zhong, W.; Cai, Z., Long-term effects of inorganic fertilizers on microbial biomass and 612 community functional diversity in a paddy soil derived from quaternary red clay. Applied Soil 613 Ecology 2007, 36 (2-3), 84-91.

614 56. Farland, J. M.; Burnside, O.; LeBaron, H. M., The Triazine Herbicides. Elsevier: Hungary, 6152011.

616 57. Armstrong, D.; Chesters, G.; Harris, R., Atrazine hydrolysis in soil. Soil Science Society of 617 America Journal 1967, 31 (1), 61-66.

618 58. Bayen, S.; Segovia, E.; Loh, L. L.; Burger, D. F.; Eikaas, H. S.; Kelly, B. C., Application 619 of polar organic chemical integrative sampler (POCIS) to monitor emerging contaminants in 620 tropical waters. Science of the Total Environment 2014, 482, $15-22$.

621 59. Mazzella, N.; Dubernet, J.-F.; Delmas, F., Determination of kinetic and equilibrium 622 regimes in the operation of polar organic chemical integrative samplers: Application to the passive 623 sampling of the polar herbicides in aquatic environments. Journal of Chromatography A 2007, $6241154(1), 42-51$.

625 60. Camilleri, J.; Morin, N.; Miège, C.; Coquery, M.; Cren-Olivé, C., Determination of the 626 uptake and release rates of multifamilies of endocrine disruptor compounds on the polar C18 627 Chemcatcher. Three potential performance reference compounds to monitor polar pollutants in surface water by integrative sampling. Journal of Chromatography A 2012, 1237, 37-45. 61. Vermeirssen, E. L.; Bramaz, N.; Hollender, J.; Singer, H.; Escher, B. I., Passive sampling combined with ecotoxicological and chemical analysis of pharmaceuticals and biocidesevaluation of three Chemcatcher ${ }^{\mathrm{TM}}$ configurations. Water Research 2009, 43 (4), 903-914.

632 62. Moschet, C.; Vermeirssen, E. L.; Singer, H.; Stamm, C.; Hollender, J., Evaluation of in633 situ calibration of Chemcatcher passive samplers for 322 micropollutants in agricultural and urban 634 affected rivers. Water research 2015, 71, 306-317.

635 63. Gunold, R.; Schafer, R.; Paschke, A.; Schuurmann, G.; Liess, M., Calibration of the 636 Chemcatcher ${ }^{\circledR}$ passive sampler for monitoring selected polar and semi-polar pesticides in surface water. Environmental Pollution 2008, 155 (1), 52-60. 
639 Table 1. IDLs of test chemicals for LC-MS and MDLs of test chemicals for lab and field 640 samples

\begin{tabular}{cccccc}
\hline \multirow{2}{*}{$\begin{array}{c}\text { Test } \\
\text { Chemicals }\end{array}$} & IDL $\left(\mu \mathrm{g} \mathrm{L}^{-1}\right)$ & \multicolumn{2}{c}{ Lab sample MDL $\left(\mu \mathrm{L} \mathrm{L}^{-1}\right)$} & \multicolumn{2}{c}{ Field sample MDL $\left(\mathrm{ng} \mathrm{L}^{-1}\right)$} \\
\cline { 2 - 5 } CHL & 0.08 & Water & DGT & Water & DGT \\
THI & 0.23 & 0.09 & 0.04 & 0.17 & 0.61 \\
FLU & 0.11 & 0.13 & 0.14 & 0.64 & 1.94 \\
ATR & 0.05 & 0.06 & 0.06 & 0.23 & 0.91 \\
PIR & 0.29 & 0.33 & 0.19 & 0.11 & 0.48 \\
LIN & 0.09 & 0.09 & 0.06 & 0.63 & 2.73 \\
PYR & 0.14 & 0.15 & 0.09 & 0.17 & 0.79 \\
CLO & 0.10 & 0.11 & 0.07 & 0.31 & 1.29 \\
ETH & 0.05 & 0.06 & 0.03 & 0.12 & 0.97 \\
\hline
\end{tabular}

641

642

643

644 Table 2. Comparison of $R_{\mathrm{S} / \mathrm{A}}^{\mathrm{b}}\left(\mathrm{mL}\left(\mathrm{d} \mathrm{cm}^{2}\right)^{-1}\right)$ for DGT at $25^{\circ} \mathrm{C}$ and some other passive samplers

\begin{tabular}{c|c|c|c|c|c|c|c|c|c}
\hline & CHL & THI & FLU & ATR & PIR & LIN & PYR & CLO & ETH \\
\hline DGT $R_{\mathrm{S} / \mathrm{A}}$ & 5.68 & 5.33 & 5.51 & 4.90 & 4.88 & 4.92 & 4.95 & 4.89 & 4.59 \\
POCIS $R_{\mathrm{S} / \mathrm{A}}$ & $-\mathrm{a}$ & $3.97^{58 \mathrm{c}}-16.77^{58 \mathrm{c}}$ & - & $0.76^{58 \mathrm{c}}-5.83^{59 \mathrm{~d}}$ & - & $3.43^{58 \mathrm{c}}-23.12^{58 \mathrm{c}}$ & - & - & - \\
$\begin{array}{c}\text { Chemcatcher } \\
R_{\mathrm{S} / \mathrm{A}}\end{array}$ & - & - & - & $4.78^{60 \mathrm{e}}-32.70^{61 \mathrm{f}}$ & $6.29^{62 \mathrm{~g}}-23.9^{63 \mathrm{~h}}$ & $3.27^{60 \mathrm{e}}-8.18^{63 \mathrm{~h}}$ & - & - & $5.03^{62 \mathrm{~g}}$ \\
\hline
\end{tabular}

645 a: no data available

646 b: $R_{\mathrm{S} / \mathrm{A}}$ values were calculated according to $R_{\mathrm{S} / \mathrm{A}}=R_{\mathrm{S}} / \mathrm{A}$ where $R_{\mathrm{S}}$ is sampling rate and $\mathrm{A}$ is

647 exposure area of the sampler. The values for A were: c: $45.8 \mathrm{~cm}^{2}$; d: $41 \mathrm{~cm}^{2}$; e, f, g, h: $15.9 \mathrm{~cm}^{2}$.

648 The temperature values were: c: $29 \pm 3{ }^{\circ} \mathrm{C}$; d: $17 \pm 1{ }^{\circ} \mathrm{C}$; e: $20^{\circ} \mathrm{C}$; f: $16.4-17.4{ }^{\circ} \mathrm{C}$; g: $5-20{ }^{\circ} \mathrm{C}$; h: 14.25

$649{ }^{\circ} \mathrm{C}$

650

651 
652 Table 3. DGT measured concentrations of ATR and its metabolites in soils expressed in $\mathrm{mg} \mathrm{L}^{-1}$

\begin{tabular}{cccccc}
\hline & Soil M & Soil D & Soil F & Soil R & Soil K \\
\hline ATR & 3.430 & 3.305 & 0.001 & 4.059 & 4.034 \\
HA & 0.331 & 0.406 & 0.029 & 0.269 & 0.141 \\
DEA & 0.042 & 0.039 & $<$ MDL & 0.007 & 0.003
\end{tabular}

653 CYA was detected in samples from soil F. As CYA cannot be eluted effectively from the HLB 654 resin gel, the data in soil $\mathrm{F}$ would not be accurate and meaningful. Terfore, it is not presented here. 

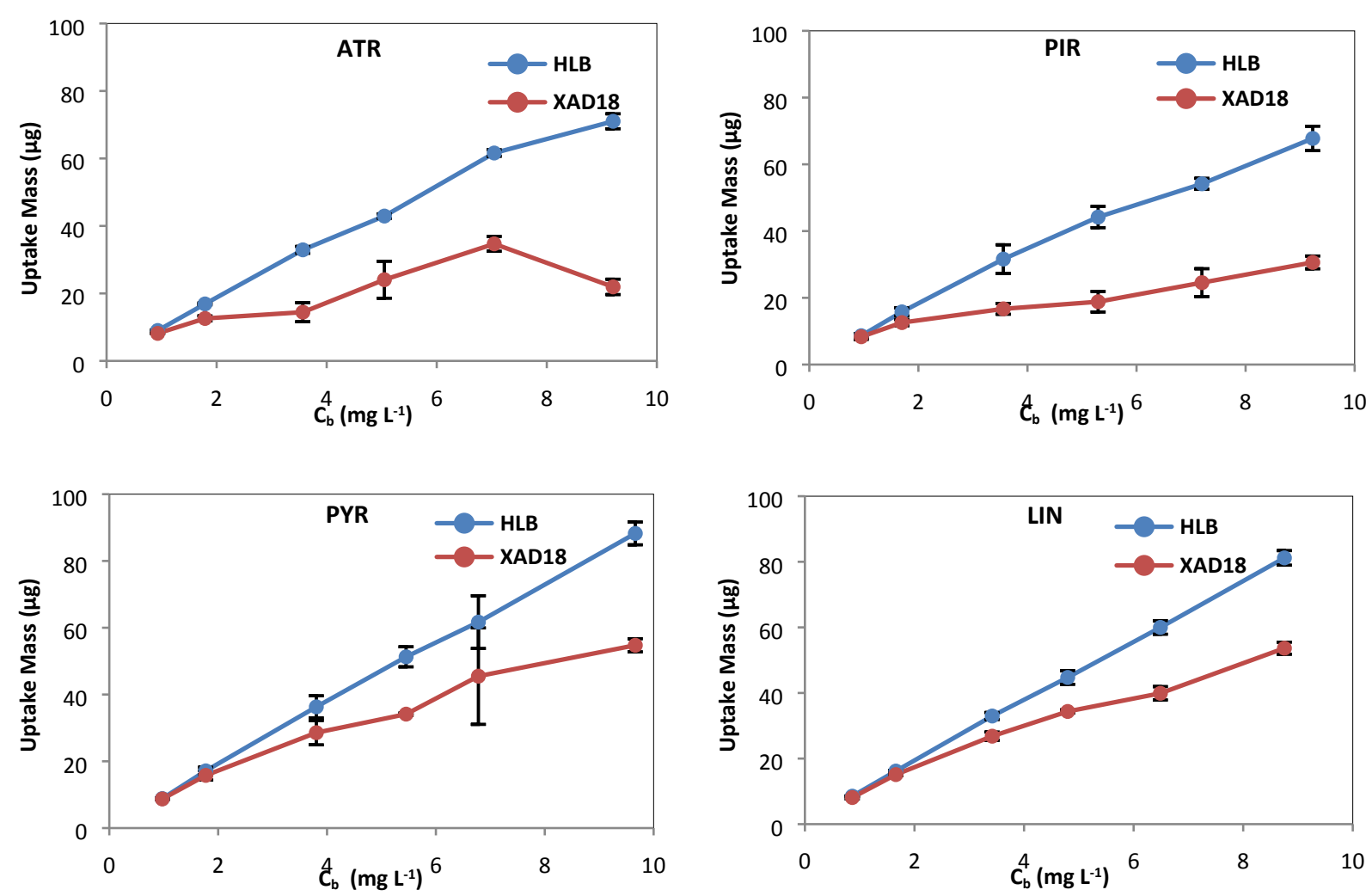

655 Figure 1. Masses of four pesticides (ATR, LIN, PIR and PYR) taken up by two types of binding 656 gels with HLB and XAD18 resins at different concentrations $\left(1-10 \mathrm{mg} \mathrm{L}^{-1}\right)(\mathrm{IS}=0.01 \mathrm{M}, \mathrm{pH}=5.8$ $657 \pm 0.2, T=20 \pm 2{ }^{\circ} \mathrm{C} ; \mathrm{n}=3$ ). Error bars were calculated from the standard deviation (SD) of three 658 replicates. 

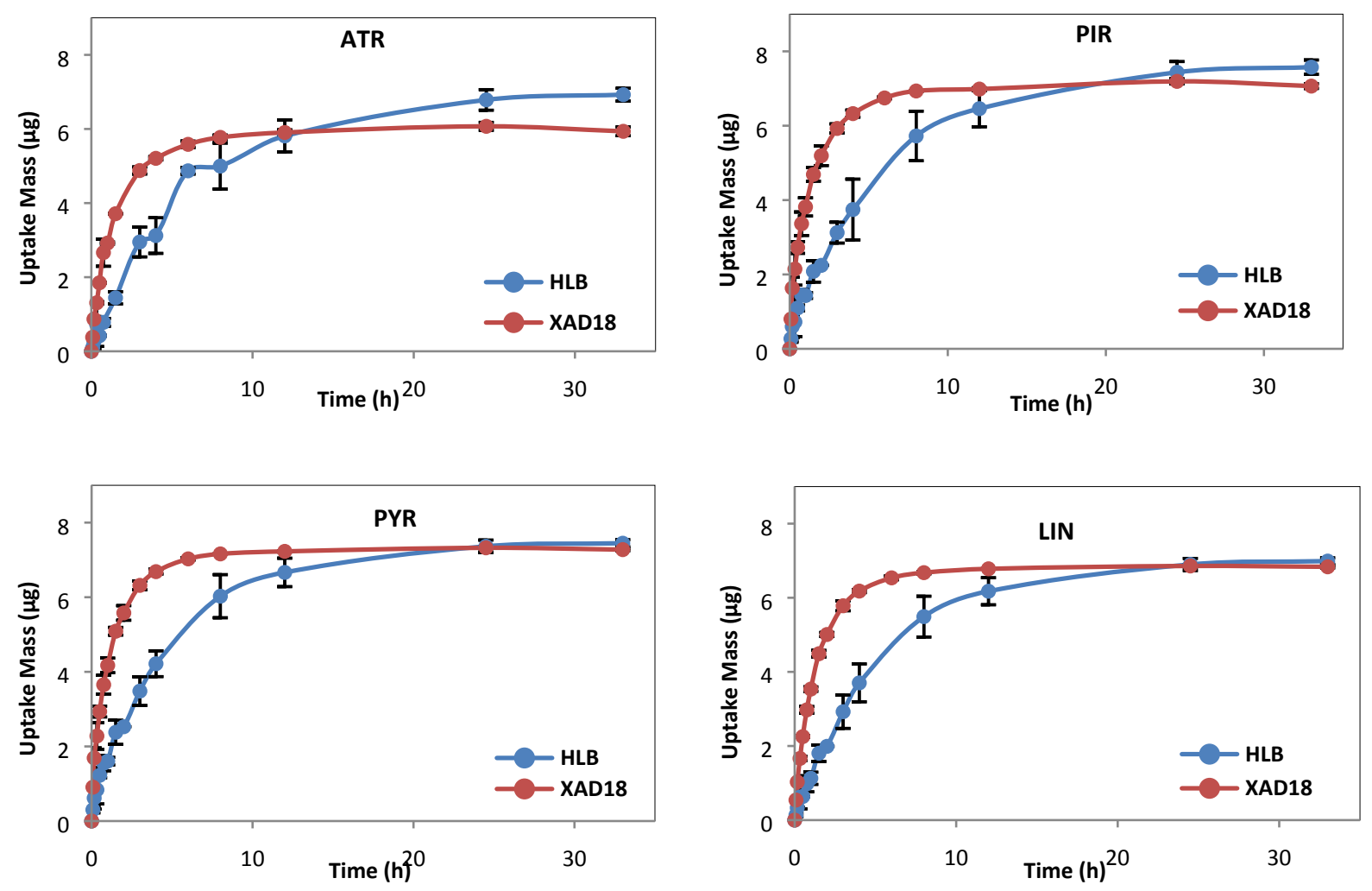

659 Figure 2. Binding kinetics of selected test chemicals by HLB and XAD18 resin gels in $40 \mathrm{~mL}$ 660 solutions of $200 \mu \mathrm{g} \mathrm{L}^{-1}$ test chemicals (IS $=0.01 \mathrm{M}, \mathrm{pH}=6.0 \pm 0.1, T=21 \pm 1{ }^{\circ} \mathrm{C} ; n=3$ ). Error 661 bars were calculated from the standard deviation (SD) of three replicates. 

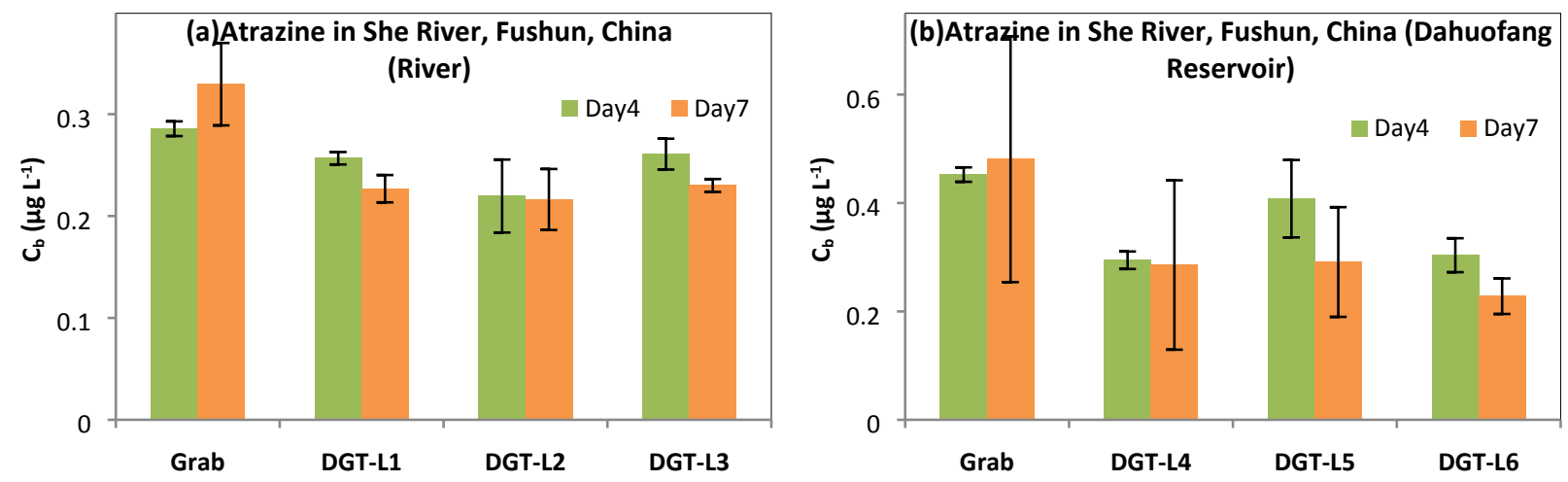

662 Figure 3. Average concentration of ATR measured by DGT devices in situ during two different 663 deployment times (4 days, in green, and 7 days, in orange) in (a) She River (in three different 664 locations, L1, L2, and L3) and (b) in Dahuofang Reservoir (in three different locations (L4, L5, 665 and L6). Grab samples were taken for both deployment period. 